\title{
Colchicine and Cardiovascular Outcomes: a Critical Appraisal of Recent Studies
}

\author{
Maciej Banach ${ }^{1,2,3}$. Peter E. Penson ${ }^{4,5}$ \\ Accepted: 14 April 2021 / Published online: 10 May 2021 \\ (C) The Author(s) 2021
}

\begin{abstract}
Purpose of Review Recent studies have demonstrated an important role for inflammation in the pathogenesis of atherosclerotic cardiovascular disease. Several studies have investigated the efficacy of colchicine (a widely used and safe anti-inflammatory drug) in patients with atherosclerosis. This review explains the rationale for the use of colchicine in this setting and critically appraises recent outcome trials.

Recent Findings Two large randomised-controlled trials LoDoCo2 (included patients with chronic coronary syndromes) and COLCOT (acute coronary syndromes) have demonstrated reductions in atherosclerotic cardiovascular events, but not mortality. A smaller study (COPS) found no beneficial effect of colchicine but was probably underpowered.

Summary Colchicine is effective at reducing cardiovascular events in chronic and acute coronary syndromes, although reductions in all-cause mortality have not been demonstrated during the period of follow-up in trials to date. Mild gastrointestinal symptoms are the most commonly reported adverse effects, although in well-designed randomised controlled trials these are relatively uncommon.
\end{abstract}

Keywords Colchicine $\cdot$ Randomised controlled trials $\cdot$ Acute coronary syndromes $\cdot$ Chronic coronary syndromes

\section{Abbreviations \\ ASCVD Atherosclerotic cardiovascular disease \\ CANTOS Canakinumab Anti-Inflammatory Thrombosis Outcomes Study}

This article is part of the Topical Collection on Coronary Heart Disease

Maciej Banach

maciej.banach@iczmp.edu.pl

Peter E. Penson

P.Penson@LJMU.AC.UK

1 Department of Hypertension, Medical University of Lodz (MUL), Rzgowska 281/289, 93-338 Lodz, Poland

2 Polish Mother's Memorial Hospital Research Institute (PMMHRI), Lodz, Poland

3 Cardiovascular Research Centre, University of Zielona Gora, Zielona Gora, Poland

4 School of Pharmacy and Biomolecular Sciences, Liverpool John Moores University, Liverpool, UK

5 Liverpool Centre For Cardiovascular Science, Liverpool, UK
CI Confidence interval

CIRT Cardiovascular Inflammation Reduction Trial

COLCOT Colchicine Cardiovascular Outcomes Trial

ColCorona Colchicine Coronavirus SARS-CoV2 Trial

COPS Colchicine in Patients with Acute Coronary Syndromes

COVID-19 Coronavirus 2019

Cox-2 Cyclooxygenase 2

CRP C-reactive protein

HR Hazard ratio

IL-1 $\beta \quad$ Interleukin- $1 \beta$

IL-6 Interleukin-6

IL-18 Interleukin-18

JUPITER Justification for the Use of Statins in Primary Prevention: an Intervention Trial Evaluating Rosuvastatin

LDL Low-density lipoprotein

LDL-C Low-density lipoprotein cholesterol

LoDoCo Low Dose Colchicine for Secondary Prevention of Cardiovascular Disease

MI Myocardial infarction

PCSK9 Proprotein convertase subtilisin/kexin type 9 


\section{Introduction}

Colchicine, an alkaloid derived from Colchicum autumnale (autumn crocus) [1], is an extremely old drug with a remarkable capacity for reinvention. Preparations of crocus have been used to treat joint pain for over 3500 years, with the active ingredient being discovered in the 1800 s. Today, colchicine is used to treat gout, familial Mediterranean fever and pericarditis [2] and has been investigated for use in the management of coronavirus 2019 (COVID-19) [3] with promising initial results recently reported from the investigators of the ColCORONA study [4, 5]. To add to this ostensibly eclectic list, studies have investigated the potential for the use of colchicine in the prevention of atherosclerotic cardiovascular disease $[6-14,15 \bullet, 16,17 \bullet \bullet, 18 \bullet \cdot$, the subject of this review.

Inflammation unites the pathology of conditions for which colchicine has established or putative indications. The mechanism of action of colchicine is complex and beyond the scope of this review. However, colchicine is a microtubule inhibitor and potentially inhibits the NLRP3 inflammasome at various points $[2,19]$ and has been shown to reduce pro-inflammatory cytokines including interleukin-1 $\beta$ (IL-1 $\beta$ ), interleukin-18 (IL-18) and interleukin-6 (IL-6), as well as the inflammatory marker C-reactive protein (CRP) in a variety of experimental models and clinical settings $[2,19]$. Recent findings relating to atherosclerosis biology and epidemiological research in cardiovascular disease strongly suggest that such effects are likely to be beneficial in the prevention of atherosclerotic cardiovascular disease in susceptible individuals. The rationale for this approach is discussed below, followed by a summary and critical overview or recent clinical research.

\section{Inflammation and Cardiovascular Disease}

Since the mid-twentieth century, remarkable progress has been made in the prevention of cardiovascular disease through the identification and management of modifiable risk factors. Observations by Gofman [20] and the Framingham investigators [21] relating to the association between elevated low-density lipoprotein cholesterol (LDL-C) and atherosclerotic cardiovascular disease, combined with improved understanding of the role of LDL-C deposition in arterial walls in atherosclerosis, led first to dietary approaches to LDL-C reduction, by reducing dietary saturated fat, and later to the development of effective lipidlowering drugs. Statins, inhibitors of endogenous LDL-C production, reduce the frequency of atherosclerotic cardiovascular events by approximately $25 \%$ for each $\mathrm{mmol} / \mathrm{L}$ reduction in LDL cholesterol, for each year of therapy [22]. Monoclonal antibody inhibitors of proprotein convertase subtilisin/kexin type 9 (PCSK9) upregulate hepatic LDL receptors, increasing clearance of LDL from the plasma, causing a substantially greater reduction in LDL-C than statins and further reductions in cardiovascular events [23]. The causal relationship between LDL-C and atherosclerosis has been firmly established [24], and prevention of cardiovascular disease should be aimed towards reducing lifelong exposure to LDL-C, according to the principle 'Lower is better for longer' $[25,26]$ and the new concept of 'the earlier the better' [26-28].

Nevertheless, even optimal management of LDL-C does not eliminate the risk of atherosclerotic cardiovascular events, and recent attention has turned towards the identification and management of the 'residual' risk. The most promising approach to date has been the targeting of inflammation. The suggestion that inflammation is an important component of atherosclerotic disease is not new. Indeed, Virchow made this observation from a pathophysiological perspective in the nineteenth century [29], an observation that has been repeated and extended by others, particularly Ross, Libby and Ridker [30, 31], and which is supported by epidemiological evidence demonstrating the association between elevated CRP and atherosclerotic events, particularly in individuals with low LDL-C [32••]. However, only recently have these observations been exploited to reduce cardiovascular risk. This delay can be explained by previous lack of knowledge of the precise molecular mechanisms involved in the inflammatory processes in atherosclerosis, lack of selective inhibitors and scepticism of this approach arising from poor outcomes when nonspecific anti-inflammatory agents such as corticosteroids have been used in the setting of acute myocardial infarction [33], and increased incidence of cardiovascular events in individuals treated with anti-inflammatory inhibitors of cyclooxygenase 2 (Cox-2) [34].

Proof of concept of the 'inflammatory hypothesis' of atherosclerosis has come in particular from the Justification for the Use of Statins in Primary Prevention: an Intervention Trial Evaluating Rosuvastatin (JUPITER) and Canakinumab AntiInflammatory Thrombosis Outcomes Study (CANTOS) studies, leading to the understanding that atherosclerosis is a lipiddriven inflammatory condition [35]. In JUPITER, 17,802 heathy individuals with what was then considered to be "normal' LDL-C ( $<130 \mathrm{mg} / \mathrm{dl},<3.4 \mathrm{mmol} / \mathrm{l})$, but elevated CRP, were randomised to receive rosuvastatin or placebo. Rosuvastatin reduced CRP, LDL-C and cardiovascular events. These results are hard to interpret, especially in light of the recent findings of the benefits of ever-lower LDL-C; however, the results of JUPITER sparked interest in the antiinflammatory mechanisms of statins $[36,37]$ and the role of inflammation in the pathophysiology of atherosclerosis. The CANTOS study evaluated the efficacy of canakinumab, a monoclonal antibody inhibitor of IL-1 $\beta$ (and like colchicine, an existing treatment for gout) in 10,061 patients with previous myocardial infarction and elevated CRP. As expected, canakinumab reduced inflammatory markers but had not effect on lipid profiles. Canakinumab treatment caused a small but statistically significant reduction in cardiovascular events and thus demonstrated that anti-inflammatory agents and 
targeting of the NLRP3 inflammasome [38, 39] could reduce the risk of atherosclerotic cardiovascular disease (ASCVD) events [40]. The relatively small benefit of canakinumab and its high acquisition cost resulted in a decision not to pursue regulatory approval for the use of canakinumab for cardiovascular indications; however, CANTOS opened the door to the use of other drugs acting on the same or related targets. In particular, substantial effort has been directed towards repurposing existing drugs, thereby benefiting from the established safety profile and (where drugs are available generically) low acquisition costs. In this context, colchicine was identified as a promising therapeutic candidate: it is cheap and has a long-established safety record.

In the treatment of gout, colchicine acts by inhibiting the components of the NLRP3 inflammasome, which is activated in response to the deposition of sodium urate crystals in soft tissue [41]. Similarly, atherosclerosis is characterised by NLRP3 activation following deposition of cholesterol crystals in the walls of blood vessels. The NLRP3 pathway is complex and involves the activation of IL- 6 by parallel mechanisms involving IL-18 and IL-1 $\beta$. Canakinumab targets IL-1 $\beta$, and recent findings have demonstrated that residual risk in canakinumab-treated patients is driven by IL-18-mediated elevation of IL-6 [42]. In this context, the demonstrated reduction of IL-18, IL-1 $\beta$ and IL- 6 by colchicine make it a very attractive theoretical candidate for the reduction of inflammatory risk in atherosclerosis.

\section{Clinical Studies of Colchicine in ASCVD}

A variety of studies have been conducted with the use of lowdose colchicine (typically $0.5-1 \mathrm{mg} /$ day) in a range of ASCVD patients (Table 1). Most studies have been of relatively short duration and have focused on surrogate outcomes in relatively small populations. The results from these studies have been somewhat inconsistent, probably reflecting differences in sample size and study design and heterogeneity in patient populations. Whilst some studies have shown no effect of colchicine on inflammatory markers $[6,11,13]$ or flowmediated dilation [12], other studies have demonstrated reductions in IL-6, IL-18, IL-1 $\beta$, caspase- 1 and increased lumen diameter $[8-10,14]$. However, it is not possible to draw inferences from these trials to inform patient care, both because of the methodological limitations listed above and because of the difficulty in translating inflammatory markers to cardiovascular outcomes or predicting outcomes based upon expected pharmacological effect. This problem is exemplified by the Cardiovascular Inflammation Reduction Trial (CIRT) in which treatment with methotrexate, an alternative antiinflammatory drug, had no effect on inflammatory markers or atherosclerotic events [46]. Previous observational studies in individuals with rheumatoid arthritis had suggested that methotrexate was associated with improved cardiovascular outcomes, compared with other anti-rheumatic drugs. However, the interpretation of such studies is inevitably complicated by confounding by indication and unmeasured biases [47]. However, it has been suggested that the prevention of atherosclerotic events by methotrexate may be limited to this population with extensive inflammation, hence the ineffectiveness of the drug in the comparatively low-risk population in CIRT [47].

The first outcome trial of colchicine in ASCVD was the Low Dose Colchicine for Secondary Prevention of Cardiovascular Disease (LoDoCo) study [7], a remarkably prescient investigation, published in 2013, before CANTOS had definitively demonstrated the causal relationship between IL-1 $\beta$ and adverse cardiovascular events. In a prospective, randomised study, 532 patients with stable coronary artery disease, the majority of whom were treated with statins and antiplatelet drugs, were randomised to colchicine treatment $(0.5 \mathrm{mg} /$ day $)$ or control and were followed for a median of 3 years for a composite primary endpoint of acute coronary syndrome, out-of-hospital cardiac arrest or non-cardioembolic ischemic stroke. The endpoint occurred in 5.3\% of participants in the colchicine group, and $16.0 \%$ of participants assigned to control (hazard ratio (HR): 0.33 ; $95 \%$ confidence interval (CI) 0.18 to $0.59 ; p<0.001$ ). Unfortunately, the study had several weaknesses which limit the extent to which the trial could influence clinical practice. The small sample size reduces the external validity of the data and increases the likelihood of drawing erroneous findings due to chance. Importantly, bias may have been introduced by the absence of placebo control or blinding of patients to their treatment allocation. Finally, the relatively short duration of followup does not permit conclusions to be drawn with respect to the long-term safety or efficacy of this therapeutic strategy.

The subsequent LoDoCo2 randomised-controlled double blind trial was substantially larger and more rigorously conducted. The LoDoCo2 investigators randomised 5522 patients with chronic coronary disease (evidence of coronary disease from angiography or coronary-artery calcium scan, and a stable clinical condition for at least 6 months) to receive $0.5 \mathrm{mg}$ colchicine daily or placebo [17••]. Patients were followed up for a median of 28.6 months for a composite endpoint comprising cardiovascular death, myocardial infarction (MI), ischaemic stroke or coronary revascularization. Colchicine treatment caused a reduction in the composite endpoint (HR, 0.69; 95\%CI, $0.57-0.83, p<0.001)$. The Kaplan-Meier curves show a clear divergence between the colchicine and placebo groups very early in the trial (circa 6 months), with the gap increasing with time $[17 \cdot 0]$. Nevertheless, the duration of follow-up was relatively short, and the data cannot be extrapolated beyond the trial duration.

In both colchicine and placebo groups, revascularisation procedures accounted for the biggest proportion of the 


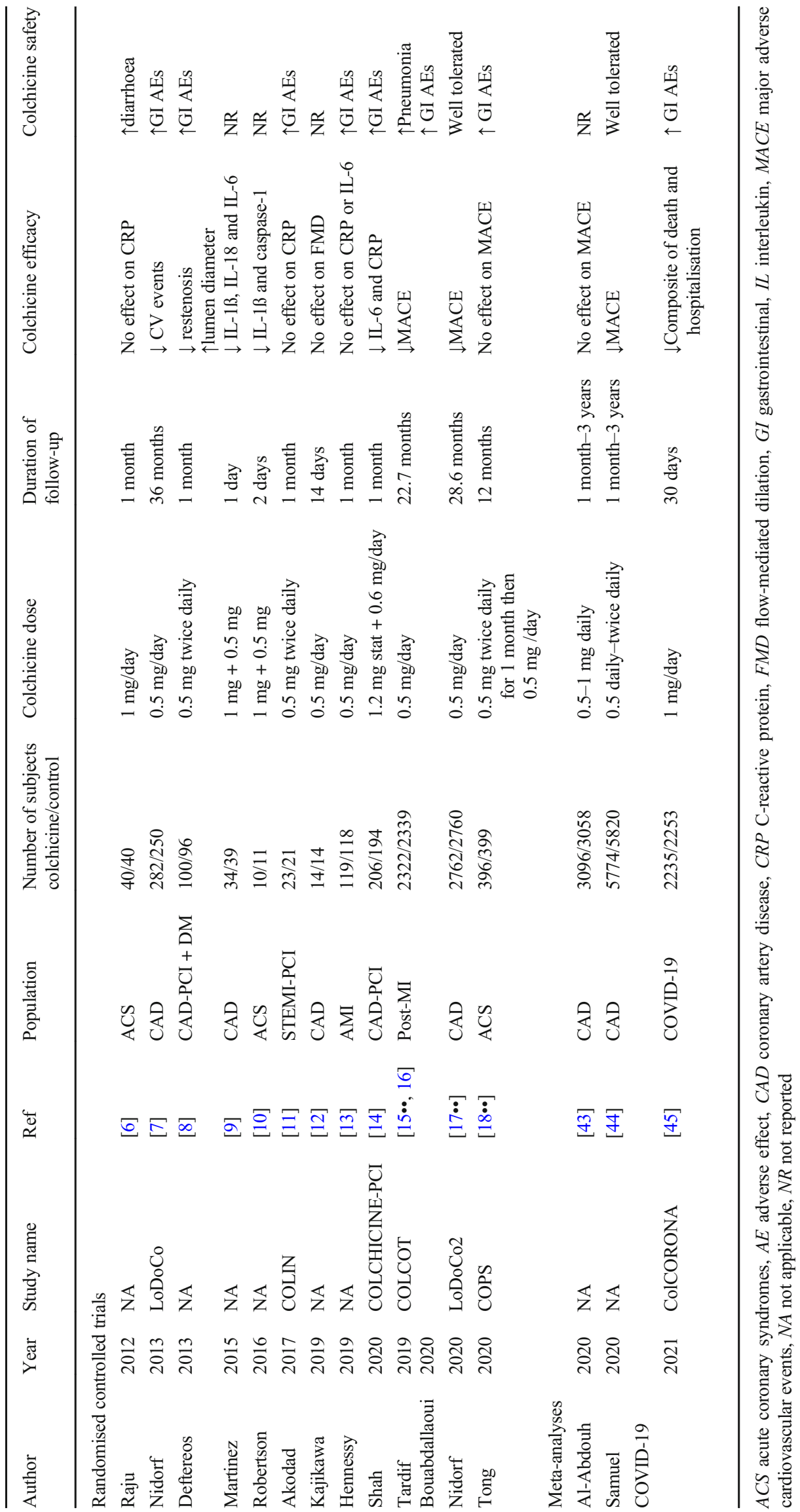


composite endpoint $[17 \bullet \bullet]$. Unlike objectively adjudicated cardiovascular death, MI or stroke ('hard' endpoints), revascularisation is somewhat 'soft' because the decision to undertake revascularisation is made by a doctor and relies upon patient consent. However, as the patients and treating physicians were unaware of treatment allocation, there is no particular reason to expect that this weakness would bias the results in any particular direction. Safety aspects are discussed in a later section.

The generalisability of the results of $\mathrm{LoDoCo} 2$ is limited by the small proportion of female subjects $(15 \%)$ enrolled in the trial. Given the complex pharmacological profile of colchicine, it would have been interesting from a scientific perspective to investigate the time course of key biomarkers throughout the trial to determine whether the drug is likely to be exerting its effects through the expected mechanisms. Unfortunately, such analysis was not possible as measurements of inflammatory markers, blood pressure and lipids were not made at baseline $[17 \bullet \bullet]$.

In contrast to the LoCoCo 2 trial, which recruited individuals with chronic coronary disease, the COLCOT trial recruited 4745 individuals who had experienced an acute coronary syndrome within 30 days, had undergone any planned revascularisation procedures and were treated according to national guidelines, which included the recommendation for high-intensity statin therapy [15••]. The composite endpoint comprised cardiovascular death, resuscitated cardiac arrest, MI, stroke or revascularisation. Treatment allocation was randomised, and neither participants nor treating physicians were aware of treatment allocations. The median duration of follow-up was slightly shorter than LoDoCo2 (22.6 v. 28.6 months). Incidence of the primary endpoint was lower in the treatment group (HR, 0.77, 95\% VI, 0.61-0.96, $p=0.02$ ). The proportion of women in the COLCOT trial was also small (19\%), and as with LoDoCo2, incomplete monitoring of biomarkers precludes mechanistic investigation of the observed effects of colchicine on outcomes.

Another recent randomised-controlled, double blind study, the Australian Colchicine in Patients with Acute Coronary Syndromes (COPS) clinical trial has also investigated the efficacy of colchicine post ACS. The authors randomised 795 patients, across 17 centres, to receive colchicine $(0.5 \mathrm{mg}$ twice daily for 1 month, then $0.5 \mathrm{mg}$ daily for 11 months) or placebo [18••]. The primary outcome was a composite of all-cause mortality, ACS, urgent revascularisation and stroke. The authors found no statistically significant benefit of treatment on the primary outcome at 12 months of follow-up. This result is clearly in contrast to COLCOT, which demonstrated a beneficial effect of colchicine on a similar primary endpoint, with a similar patient population, and LoDoCo 2 which recruited patients with chronic coronary syndromes. The most likely explanation for the difference is the low statistical power in the COPS trial, which was an investigator-led trial, and despite setting up 17 recruitment sites, budgetary issues limited the ability of the investigators to recruit and follow up patients [18••]. As a result, the analyses in COPS were based upon 62 primary endpoint events, compared to a combined total of 752 events in COLCOT and LoDoCo2 [48]. Therefore, the results of this trial also should be treated with caution and would be most useful when synthesised with the findings from related studies in a meta-analysis, although the higher initial dose in COPS may result in substantial heterogeneity and may explain differences between the findings of the three trials.

None of the randomised-controlled outcome trials (LoDoCo2, COLCOT and COPS) demonstrated a reduction in mortality associated with colchicine treatment. It is not clear whether this reflects the fact that colchicine is truly neutral with respect to mortality or whether it is explained by insufficient statistical power. In the COPS study, colchicine treatment was, in fact, associated with an increase in mortality compared to placebo (8 v. 1 deaths). Similarly, in LoDoCo2, there was a numerically greater number of deaths in the treatment group (73 v. 60 deaths; HR, 1.21 ; 95\%CI $0.86-$ 1.71). In COLCOT, the number of deaths was almost identical (43 v. 44 deaths; HR, 0.98; 95\%CI 0.64-1.49). The wide confidence intervals around these estimates indicate that it is likely that any differences are due to the play of chance. Given the long history of colchicine use, the numerical increases in mortality on treatment in two trials should not be a particular concern, but mortality should be followed up, where possible, in existing cohorts to gather more data $[15 \bullet \bullet, 17 \bullet \bullet, 18 \bullet \bullet, 48]$.

These findings have been confirmed by a recently completed study-level meta-analysis, conducted on behalf of the International Lipid Expert Panel, which is currently in peer review. The meta-analysis included 12 randomised-controlled trials, with a total of 12,989 patients, with a mean follow-up of 22.6 months. Colchicine treatment was associated with a lower risk of major adverse cardiovascular events (RR 0.67; 95\%CI 0.6-0.92, $P=0.004$ ); CRP and IL-6 (but not other inflammatory markers) were significantly reduced. There was no apparent effect of colchicine upon mortality [49].

Each of the randomised-controlled outcome trials (LoDoCo2, COLCOT and COPS) also measured safety outcomes. As would be expected with a drug which acts by reducing inflammatory/immune mechanisms, particular attention was paid to the possibility of increased rates of infection in colchicine-treated patients. In COLCOT, treatment was associated with a small increase in the incidence of pneumonia $(0.9 \%$ v. $0.4 \%)$, whereas this effect was not observed in

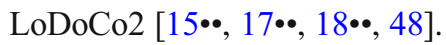

Almost all trials reported increased frequency of gastrointestinal adverse effects (particularly diarrhoea) in colchicinetreated patients. As this effect has been consistently demonstrated in randomised studies, it is likely to indicate a causal relationship. However, it is important not to overestimate the 
potential importance of this effect to limit treatment. In the LoDoCo2 trial, a pre-randomisation run-in period was used, in which potential participants who experienced adverse effects left the trial before allocation to colchicine or placebo $[17 \cdot \bullet]$. Thus, the reported adverse effects in the randomised portion of the trial are likely to underestimate the expected prevalence in clinical practice. However, the COLCOT trial used no such run-in and therefore perhaps gives a better estimate. In this trial, diarrhoea was reported in $9.7 \%$ of patients in the treatment group compared with $8.9 \%$ in the placebo group. Thus, this is a small effect, albeit a well-known one. Extensive evidence from statin trials has indicated that the drucebo effect (whereby a patient experiences adverse drug reactions as a result of expecting such effects) accounts for a substantial proportion of reported muscle pain in patients receiving these drugs for hypercholesterolemia. This can limit the adherence to life-saving preventative drugs [50-52]. Because gastrointestinal symptoms are common (so symptoms from unrelated causes are misattributed to colchicine) and can be triggered psychosomatically, it seems likely that the drucebo effect might be expected to apply to colchicine therapy. Thus, if colchicine is to be used widely in the prevention of ASCVT, it is important to make patients aware of the relative infrequency and reversibility of adverse effects.

All the three outcomes trials to date have been conducted in

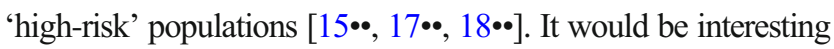
in the future to determine whether colchicine reduces the incidence of ACVD events in a lower-risk primary-prevention population. Whilst such an approach has potential benefits, it also presents several challenges. The absolute benefit of any intervention is likely to be smaller in a low-risk population, so the potential for adverse effects might weigh more heavily against treatment in a low-risk population. Furthermore, as colchicine is no longer covered by patents, a new indication is unlikely to generate substantial revenue; thus, funding for clinical trials may be hard to secure. However, the evaluation of colchicine in larger populations could be achieved by including combining it with another intervention in a randomised trial with factorial design. Alternatively, the low cost of colchicine could make it suitable for evaluation together with other anti-atherosclerotic agents in a polypill preparation [53].

\section{Conclusions}

Low-dose colchicine has been shown to reduce cardiovascular events in patients with acute and chronic coronary syndromes in two large outcomes trials, in which the drug was generally well tolerated. No indication has been found that colchicine reduces mortality, although additional studies or longer follow-up of existing trials is required to possibly confirm this fact. In smaller trials, the effects of colchicine have been variable with respect to the effect of the drug on outcomes and inflammatory markers.

\section{Declaration}

Conflict of Interest PEP owns four shares in AstraZeneca PLC and has received honoraria and/or travel reimbursement for events sponsored by AKCEA, Amgen, AMRYT, Link Medical, Mylan, Napp, Sanofi.

MB reports Speakers bureau from the following: Abbott/Mylan, Akcea, Amgen, Daichii Sankyo, KRKA, MSD, Novartis, NovoNordisk, Polpharma, Sanofi, Servier; consultant to Akcea, Amgen, Daichii Sankyo, Esperion, Freia Pharmaceuticals, Herbapol, Kogen, MSD, Polfarmex, Resverlogix, Sanofi/Regeneron, Teva, Zentiva; Grants from Amgen, Mylan, Sanofi and Valeant.

Human and Animal Rights and Informed Consent This article does not contain any studies with human or animal subjects performed by any of the authors.

Open Access This article is licensed under a Creative Commons Attribution 4.0 International License, which permits use, sharing, adaptation, distribution and reproduction in any medium or format, as long as you give appropriate credit to the original author(s) and the source, provide a link to the Creative Commons licence, and indicate if changes were made. The images or other third party material in this article are included in the article's Creative Commons licence, unless indicated otherwise in a credit line to the material. If material is not included in the article's Creative Commons licence and your intended use is not permitted by statutory regulation or exceeds the permitted use, you will need to obtain permission directly from the copyright holder. To view a copy of this licence, visit http://creativecommons.org/licenses/by/4.0/.

\section{References}

Papers of particular interest, published recently, have been highlighted as:

- Of importance

•. Of major importance

1. Evans WC, Evans D. Chapter 6-Pharmacological activities of natural products. In: Evans WC, Evans D, editors. Trease and Evans' pharmacognosy. sixteenth ed: W.B. Saunders; 2009. p. 45-52.

2. Dasgeb B, Kornreich D, McGuinn K, Okon L, Brownell I, Sackett DL. Colchicine: an ancient drug with novel applications. Br J Dermatol. 2018;178(2):350-6. https://doi.org/10.1111/bjd.15896.

3. Deftereos SG, Giannopoulos G, Vrachatis DA, Siasos GD, Giotaki SG, Gargalianos P, et al. Effect of colchicine vs standard care on cardiac and inflammatory biomarkers and clinical outcomes in patients hospitalized with coronavirus disease 2019: the GRECCO-19 Randomized Clinical Trial. JAMA Netw Open. 2020;3(6): e2013136. https://doi.org/10.1001/jamanetworkopen.2020.13136.

4. Wendling P. ColCORONA: colchicine reduces complications in outpatient COVID-19. Medscape Medical News. 2021. https://www.medscape.com/viewarticle/944593.

5. ColCORONA trial investigators. Colchicine Coronavirus SARSCoV2 Trial Clinicaltrialsgov NCT04322682. 2020. https:// clinicaltrials.gov/ct2/show/NCT04322682. 
6. Raju NC, Yi Q, Nidorf M, Fagel ND, Hiralal R, Eikelboom JW. Effect of colchicine compared with placebo on high sensitivity Creactive protein in patients with acute coronary syndrome or acute stroke: a pilot randomized controlled trial. J Thromb Thrombolysis. 2012;33(1):88-94. https://doi.org/10.1007/s11239-011-0637-y.

7. Nidorf SM, Eikelboom JW, Budgeon CA, Thompson PL. Lowdose colchicine for secondary prevention of cardiovascular disease. J Am Coll Cardiol. 2013;61(4):404-10. https://doi.org/10.1016/j. jacc.2012.10.027.

8. Deftereos S, Giannopoulos G, Raisakis K, Kossyvakis C, Kaoukis A, Panagopoulou V, et al. Colchicine treatment for the prevention of bare-metal stent restenosis in diabetic patients. J Am Coll Cardiol. 2013;61(16):1679-85. https://doi.org/10.1016/j.jacc. 2013.01.055.

9. Martinez GJ, Robertson S, Barraclough J, Xia Q, Mallat Z, Bursill $\mathrm{C}$, et al. Colchicine acutely suppresses local cardiac production of inflammatory cytokines in patients with an acute coronary syndrome. J Am Heart Assoc. 2015;4(8):e002128. https://doi.org/10. 1161/JAHA.115.002128.

10. Robertson S, Martinez GJ, Payet CA, Barraclough JY, Celermajer DS, Bursill C, et al. Colchicine therapy in acute coronary syndrome patients acts on caspase-1 to suppress NLRP3 inflammasome monocyte activation. Clin Sci (Lond). 2016;130(14):1237-46. https://doi.org/10.1042/CS20160090.

11. Akodad M, Lattuca B, Nagot N, Georgescu V, Buisson M, Cristol JP, et al. COLIN trial: value of colchicine in the treatment of patients with acute myocardial infarction and inflammatory response. Arch Cardiovasc Dis. 2017;110(6-7):395-402. https://doi.org/10. 1016/j.acvd.2016.10.004.

12. Kajikawa M, Higashi Y, Tomiyama H, Maruhashi T, Kurisu S, Kihara Y, et al. Effect of short-term colchicine treatment on endothelial function in patients with coronary artery disease. Int $\mathrm{J}$ Cardiol. 2019;281:35-9. https://doi.org/10.1016/j.ijcard.2019.01. 054.

13. Hennessy T, Soh L, Bowman M, Kurup R, Schultz C, Patel S, et al. The Low Dose Colchicine after Myocardial Infarction (LoDoCoMI) study: a pilot randomized placebo controlled trial of colchicine following acute myocardial infarction. Am Heart J. 2019;215:62-9. https://doi.org/10.1016/j.ahj.2019.06.003.

14. Shah B, Pillinger M, Zhong H, Cronstein B, Xia Y, Lorin JD, et al. Effects of acute colchicine administration prior to percutaneous coronary intervention: COLCHICINE-PCI Randomized Trial. Circ Cardiovasc Interv. 2020;13(4):e008717. https://doi.org/10. 1161/CIRCINTERVENTIONS.119.008717.

15.• Tardif JC, Kouz S, Waters DD, Bertrand OF, Diaz R, Maggioni AP, et al. Efficacy and safety of low-dose colchicine after myocardial infarction. N Engl J Med. 2019;381(26):2497-505. https:// doi.org/10.1056/NEJMoa1912388. This paper reports the results of the COLCOT study.

16. Bouabdallaoui N, Tardif JC, Waters DD, Pinto FJ, Maggioni AP, Diaz R, et al. Time-to-treatment initiation of colchicine and cardiovascular outcomes after myocardial infarction in the Colchicine Cardiovascular Outcomes Trial (COLCOT). Eur Heart J. 2020;41(42):4092-9. https://doi.org/10.1093/eurheartj/ehaa659.

17.• Nidorf SM, Fiolet ATL, Mosterd A, Eikelboom JW, Schut A, Opstal TSJ, et al. Colchicine in patients with chronic coronary disease. N Engl J Med. 2020;383(19):1838-47. https://doi.org/ 10.1056/NEJMoa2021372. This paper reports the results of the LoDoCo2 study.

18.• Tong DC, Quinn S, Nasis A, Hiew C, Roberts-Thomson P, Adams $\mathrm{H}$, et al. Colchicine in patients with acute coronary syndrome: the Australian COPS Randomized Clinical Trial. Circulation. 2020;142(20):1890-900. https://doi.org/10.1161/ CIRCULATIONAHA.120.050771. This paper reports the results of the COPS study.
19. Marques-da-Silva C, Chaves MM, Castro NG, Coutinho-Silva R, Guimaraes MZ. Colchicine inhibits cationic dye uptake induced by ATP in P2X2 and P2X7 receptor-expressing cells: implications for its therapeutic action. Br J Pharmacol. 2011;163(5):912-26. https:// doi.org/10.1111/j.1476-5381.2011.01254.x.

20. Gofman JW, Young W, Tandy R. Ischemic heart disease, atherosclerosis, and longevity. Circulation. 1966;34(4):679-97. https:// doi.org/10.1161/01.cir.34.4.679.

21. Wilson PW, D'Agostino RB, Levy D, Belanger AM, Silbershatz H, Kannel WB. Prediction of coronary heart disease using risk factor categories. Circulation. 1998;97(18):1837-47. https://doi.org/10. 1161/01.cir.97.18.1837.

22. Collins R, Reith C, Emberson J, Armitage J, Baigent C, Blackwell $\mathrm{L}$, et al. Interpretation of the evidence for the efficacy and safety of statin therapy. Lancet. 2016;388(10059):2532-61. https://doi.org/ 10.1016/S0140-6736(16)31357-5.

23. Banach M, Penson PE. What have we learned about lipids and cardiovascular risk from PCSK9 inhibitor outcome trials: ODYSSEY and FOURIER? Cardiovasc Res. 2019;115(3):e2631. https://doi.org/10.1093/cvr/cvy301.

24. Ference BA, Ginsberg HN, Graham I, Ray KK, Packard CJ, Bruckert E, et al. Low-density lipoproteins cause atherosclerotic cardiovascular disease. 1. Evidence from genetic, epidemiologic, and clinical studies. A consensus statement from the European Atherosclerosis Society Consensus Panel. Eur Heart J. 2017;38(32):2459-72. https://doi.org/10.1093/eurheartj/ehx144.

25. Penson PE, Pirro M, Banach M. LDL-C: lower is better for longer-even at low risk. BMC Med. 2020;18(1):1-6. https://doi. org/10.1186/s12916-020-01792-7.

26. Cybulska B, Klosiewicz-Latoszek L, Penson PE, Nabavi SM, Lavie CJ, Banach M, et al. How much should LDL cholesterol be lowered in secondary prevention? Clinical efficacy and safety in the era of PCSK9 inhibitors. Prog Cardiovasc Dis. 2020. https://doi.org/10. 1016/j.pcad.2020.12.008.

27. Banach M, Penson PE. Lipid-lowering therapies: better together. Atherosclerosis. 2021;320:86-8. https://doi.org/10.1016/j. atherosclerosis.2021.01.009.

28. Banach M, Penson PE. Statins and LDL-C in secondary prevention - so much progress, so far to go. JAMA Netw Open. 2020;3(11):e2025675. https://doi.org/10.1001/jamanetworkopen. 2020.25675 .

29. Virchow R. Cellular pathology. As based upon physiological and pathological histology. Lecture XVI-Atheromatous affection of arteries. 1858. Nutr Rev. 1989 Jan;47(1):23-5. https://doi.org/10. 1111/j.1753-4887.1989.tb02747.x.

30. Ross R. Atherosclerosis - an inflammatory disease. N Engl J Med. 1999;340(2):115-26. https://doi.org/10.1056/ NEJM199901143400207.

31. Libby P, Ridker PM, Hansson GK. Leducq Transatlantic Network on A. Inflammation in atherosclerosis: from pathophysiology to practice. J Am Coll Cardiol. 2009;54(23):2129-38. https://doi. org/10.1016/j.jacc.2009.09.009.

32.• Penson PE, Long DL, Howard G, Toth PP, Muntner P, Howard $\mathrm{VJ}$, et al. Associations between very low concentrations of low density lipoprotein cholesterol, high sensitivity C-reactive protein, and health outcomes in the Reasons for Geographical and Racial Differences in Stroke (REGARDS) study. Eur Heart J. 2018;39(40):3641-53. https://doi.org/10.1093/eurheartj/ehy533.

This study provides epidemiological evidence for the importance of inflammatory markers in the prediction of cardiovascular events.

33. Giugliano GR, Giugliano RP, Gibson CM, Kuntz RE. Metaanalysis of corticosteroid treatment in acute myocardial infarction. Am J Cardiol. 2003;91(9):1055-9. https://doi.org/10.1016/s00029149(03)00148-6. 
34. Patrono C. Cardiovascular effects of cyclooxygenase-2 inhibitors: a mechanistic and clinical perspective. Br J Clin Pharmacol. 2016;82(4):957-64. https://doi.org/10.1111/bcp.13048.

35. Libby P, Buring JE, Badimon L, Hansson GK, Deanfield J, Bittencourt MS, et al. Atherosclerosis. Nat Rev Dis Primers. 2019;5(1):56. https://doi.org/10.1038/s41572-019-0106-z.

36. Shahbaz SK, Sadeghi M, Koushki K, Penson PE, Sahebkar A. Regulatory T cells: possible mediators for the anti-inflammatory action of statins. Pharmacol Res. 2019;149:104469. https://doi. org/10.1016/j.phrs.2019.104469.

37. Ganjali S, Bianconi V, Penson PE, Pirro M, Banach M, Watts GF, et al. Commentary: Statins, COVID-19, and coronary artery disease: killing two birds with one stone. Metabolism. 2020;113: 154375. https://doi.org/10.1016/j.metabol.2020.154375.

38. Swanson KV, Deng M, Ting JP. The NLRP3 inflammasome: molecular activation and regulation to therapeutics. Nat Rev Immunol. 2019;19(8):477-89. https://doi.org/10.1038/s41577-019-0165-0.

39. Jin $\mathrm{Y}, \mathrm{Fu}$ J. Novel insights into the NLRP 3 inflammasome in atherosclerosis. J Am Heart Assoc. 2019;8(12):e012219. https:// doi.org/10.1161/JAHA.119.012219.

40. Ridker PM, Everett BM, Thuren T, MacFadyen JG, Chang WH, Ballantyne C, et al. Antiinflammatory therapy with canakinumab for atherosclerotic disease. N Engl J Med. 2017;377(12):1119-31. https://doi.org/10.1056/NEJMoa1707914.

41. Dalbeth N, Merriman TR, Stamp LK. Gout. lancet. 2016;388(10055):2039-52. https://doi.org/10.1016/s01406736(16)00346-9.

42. Ridker PM, MacFadyen JG, Thuren T, Libby P. Residual inflammatory risk associated with interleukin-18 and interleukin- 6 after successful interleukin-1beta inhibition with canakinumab: further rationale for the development of targeted anti-cytokine therapies for the treatment of atherothrombosis. Eur Heart J. 2020;41(23): 2153-63. https://doi.org/10.1093/eurheartj/ehz542.

43. Al-Abdouh A, Barbarawi M, Khan SU, Osman M, Upadhrasta S, Solipuram V, et al. Colchicine therapy in patients with coronary artery disease: a systematic review and meta-analysis of randomized controlled trials. Coron Artery Dis. 2020. https://doi.org/10. 1097/MCA.0000000000000931.

44. Samuel M, Tardif JC, Bouabdallaoui N, Khairy P, Dube MP, Blondeau L, et al. Colchicine for secondary prevention of cardiovascular disease: a systematic review and meta-analysis of randomized controlled trials. Can J Cardiol. 2020. https://doi.org/10.1016/j. cjca.2020.10.006.
45. Tardif J-C, Bouabdallaoui N, L'Allier PL, Gaudet D, Shah B, Pillinger $\mathrm{MH}$ et al. Efficacy of colchicine in non-hospitalized patients with COVID-19. medRxiv. 2021:2021.01.26.21250494. https://doi.org/10.1101/2021.01.26.21250494.

46. Ridker PM, Everett BM, Pradhan A, MacFadyen JG, Solomon DH, Zaharris E, et al. Low-dose methotrexate for the prevention of atherosclerotic events. N Engl J Med. 2019;380(8):752-62. https://doi. org/10.1056/NEJMoa1809798.

47. Reiner Z, Sirtori CR, Banach M, Ruscica M, Sahebkar A. Methotrexate for cardiovascular risk reduction: the right choice? Angiology. 2020;71(2):105-7. https://doi.org/10.1177/ 0003319719855165.

48. Roubille F, Tardif JC. Colchicine for secondary cardiovascular prevention in coronary disease. Circulation. 2020;142(20):1901-4. https://doi.org/10.1161/CIRCULATIONAHA.120.051240.

49. Bytyçi I, Bajraktari G, Penson PE, Henein MY, Banach M, International Lipid Expert Panel. Efficacy and safety of colchicine in patients with coronary artery disease: a systematic review and meta-analysis of randomized controlled trials. Data unpublished. 2021.

50. Banach M, Penson P. Drucebo effect - the challenge we should all definitely face! Arch Med Sci. 2021. https://doi.org/10.5114/aoms/ 132304.

51. Penson PE, Mancini GBJ, Toth PP, Martin SS, Watts GF, Sahebkar A, et al. Introducing the 'Drucebo' effect in statin therapy: a systematic review of studies comparing reported rates of statin-associated muscle symptoms, under blinded and open-label conditions. J Cachexia Sarcopenia Muscle. 2018;9(6):1023-33. https://doi.org/ 10.1002/jcsm. 12344 .

52. Wood FA, Howard JP, Finegold JA, Nowbar AN, Thompson DM, Arnold AD, et al. N-of-1 trial of a statin, placebo, or no treatment to assess side effects. N Engl J Med. 2020;383(22):2182-4. https:// doi.org/10.1056/NEJMc2031173.

53. Franczyk B, Gluba-Brzozka A, Jurkiewicz L, Penson P, Banach M, Rysz J. Embracing the polypill as a cardiovascular therapeutic: is this the best strategy? Expert Opin Pharmacother. 2018;19(17): 1857-65. https://doi.org/10.1080/14656566.2018.1532501.

Publisher's Note Springer Nature remains neutral with regard to jurisdictional claims in published maps and institutional affiliations. 